\title{
Perioperative Management of Pulmonary Hypertension
}

\author{
Philip L. Kalarickal, Sabrina T. Bent, \\ Michael J. Yarborough, Kavitha A. Mathew and Charles Fox \\ Department of Anesthesiology, Tulane University School of Medicine, New Orleans, LA \\ United States of America
}

\section{Introduction}

Pulmonary hypertension is the manifestation of a disorder of the pulmonary vascular bed, which results in obstruction of pulmonary blood flow. Although many different causes exist, hypertension in the pulmonary circulation is the result of increased vascular resistance, increased vascular bed flow, or both. The signs and symptoms of pulmonary hypertension are nonspecific and subtle. Left untreated, patients will experience progressive symptoms of dyspnea and right heart failure culminating in a markedly curtailed survival [Gaine, 2000]. Idiopathic pulmonary arterial hypertension is a relatively rare disease of unknown cause [Lloyd et al, 1995]; however, in the perioperative arena the majority of patients encountered with pulmonary hypertension have acquired it secondary to a cardiac or a pulmonary disease process. Left sided ventricular or atrial disease and left sided valvular heart disease are common causes of pulmonary hypertension. Both of these conditions elevate left atrial pressure and passively increase pulmonary venous pressure, pulmonary artery pressure (PAP), and pulmonary vascular resistance (PVR). Multiple respiratory diseases lead to the development of pulmonary hypertension via a hypoxia-induced vasoconstriction [Phillips et al, 1999]. Regardless of causation, all pathways lead to an altered vascular endothelium and smooth muscle function through cellular remodeling [MacLean, 1999; Tuder et al, 2001]. This results in increased vascular contractility or lack of vascular relaxation in response to various endogenous vasodilator substances. Detailed discussion of the pathology, pathophysiology, evaluation and treatment are provided elsewhere in this text and via consensus statements from the American College of Cardiology/American Heart Association. [McLaughlin et al, 2009]

From a clinical anesthesia standpoint, although mild pulmonary hypertension rarely impacts anesthetic management, severe or moderate pulmonary hypertension can lead to acute right heart failure (RHF) and cardiogenic shock. The perioperative management of patients with pulmonary hypertension varies depending upon the pathological features present, functional clinical classification (Table 1), hemodynamics, and success of current medical therapy. This chapter will provided an overview of the pre-operative evaluation, intraoperative considerations, management strategies and postoperative considerations. 


\begin{tabular}{|c|c|c|c|}
\hline Class I & Class II & Class III & Class IV \\
\hline $\begin{array}{l}\text { does not cause undue } \\
\text { dyspnea or fatigue, } \\
\text { chest pain or near syncope }\end{array}$ & $\begin{array}{l}\text { at rest, but ordinary physical activity } \\
\text { causes undue dyspnea or fatigue, } \\
\text { chest pain or near syncope }\end{array}$ & $\begin{array}{l}\text { at rest, but less than ordinary } \\
\text { physical activity causes undue } \\
\text { dyspnea or fatigue, chest pain } \\
\text { or near syncope }\end{array}$ & $\begin{array}{l}\text { These patients manifest } \\
\text { signs of right heart } \\
\text { failure } \\
\text { Dyspnea and fatigue } \\
\text { may be present at rest, } \\
\text { and discomfort is } \\
\text { increased by any } \\
\text { physical activity }\end{array}$ \\
\hline
\end{tabular}

${ }^{*}$ Modified from the New York Heart Association classification of patients with cardiac disease.

Table 1. Functional Assessment of the patient with pulmonary hypertension.

\section{Preoperative evaluation and preparation}

Surgery for patients with pulmonary hypertension is associated with significant morbidity and mortality regardless of the anesthetic technique utilized [Krowka et al, 2004; Martin et al, 2002; Ramakrishna et al, 2005; Roberts \& Keast 1990; Tan et al 2001; Weiss \& Atanassoff, 1993]. For example, patients with Eisenmenger's syndrome undergoing cesarean section have had mortality reported as high as 70\% [Kahn, 1993]. Although there is not an overabundance of literature regarding the development of postoperative pulmonary complications following noncardiac surgery, the few studies that do exist demonstrate the risk associated with procedures. Therefore, medical optimization is critical. During perioperative risk assessment, one should take into account the type of surgery, the patient's functional status, the severity of the pulmonary hypertension, the function of the right ventricle and any co-morbidities. Superficial procedures and non-orthopedic procedures will be associated with less hemodynamic and sympathetic nervous system perturbations than more invasive procedures. Orthopedic procedures with bony involvement can be quite stimulating for the patient and will increase the risk of increases in PVR and RV failure. Thoracic surgery is associated with changes in intrathoracic pressures, lung volumes and oxygenation, which may cause acute increases in PVR and decreased RV function [Ross AF et al., 2010]. Laparoscopic surgery requires pneumoperitoneum which may be poorly tolerated because it can decrease preload and increase afterload. Procedures associated with rapid blood loss may be poorly tolerated.

\subsection{History and physical exam}

Preoperative evaluation should include a thorough history and physical examination with special attention paid to signs and symptoms of right ventricular dysfunction. Symptoms are typically nonspecific with the most frequent being progressive dyspnea. The signs present depend on disease severity with dyspnea at rest, low cardiac output with metabolic acidosis, hypoxemia, evidence of right heart failure (large $\mathrm{V}$ wave on jugular vein, peripheral edema, hepatomegaly), and syncope being useful indicators [Blaise et al, 2003]. Laboratory studies should be directed according to the procedure that the patient is undergoing and the medication profile of the patient. Tests that should be strongly considered include electrocardiography, chest radiographs, echocardiography, and possibly right heart catheterization. In addition, depending on severity of the pulmonary hypertension, the following studies may also be useful, especially in the initial workup or depending on causes: 
pulmonary function testing, arterial blood gas analysis, ventilation/perfusion scanning, pulmonary angiography, spiral computed tomography, serologic testing, and liver function testing. The ECG may demonstrate signs of right ventricular hypertrophy, such as tall right precordial $\mathrm{R}$ waves, right axis deviation and right ventricular strain [Nauser \& Stites, 2001], but ECG changes alone cannot determine disease severity or prognosis [Ahearn et al, 2002; Bossone et al, 2002]. The chest radiograph may show evidence of right ventricular hypertrophy (decreased retrosternal space) or prominent pulmonary vasculature.

Among the myriad of available tests, echocardiography is the screening method of choice. Echocardiography may be useful to show right ventricular hypertrophy and to estimate pulmonary arterial pressure [Blaise et al, 2003]. Right heart catheterization is the gold standard for measuring pulmonary arterial pressures, however. Evidence of significant right ventricular dysfunction should prompt reevaluation of the need for surgery [Pearl, 2005]. All attempts to lower pulmonary arterial pressure should be done prior to surgery. Treatment options include oxygen, bronchodilators, vasodilators and inotropes. In addition to the careful evaluation of the patient's current therapeutic regimen for pulmonary hypertension, all other medications should be reviewed for possible interactions with others that may need to be instituted while under anesthesia. Likewise, it is important to maintain the patient's current therapeutic regimen as withdrawal of medications can lead to rebound pulmonary hypertension and RV dysfunction. Although medications such as inhaled prostacyclin (epoprostenol or Flolan ${ }^{\circledR}$ ) are associated with impaired platelet aggregation, they have not been implicated in clinically significant bleeding. Due to the short half-life of this medication, epoprostenol should not be stopped at any time in the perioperative period. The anesthesiologist must ensure preoperative maximization of the patient's therapeutic options has been accomplished and coordinate, if needed, a strategy for continuance of chronic pulmonary hypertension therapy perioperatively.

\subsection{Perioperative care team coordination}

The major physiologic consideration for patients with pulmonary hypertension is the effect of increased PVR on right ventricular function. The induction and maintenance of general anesthesia coupled with positive pressure ventilation can cause dramatic hemodynamic effects in the patient with pulmonary arterial hypertension. These patients have an increased risk of developing significant cardiac dysfunction and have an increased risk of perioperative cardiovascular complications [Carmosino et al, 2007; Subramaniam \& Yared, 2007]. Because of this, after preoperative data have been collected and reviewed, it is imperative that the anesthesiologist understands the causes and pathophysiology of the patient's disease so that a therapeutic perioperative regimen and anesthetic plan can be established. Although major advancements in treatment have prolonged survival and improved these patients' quality of life, no current therapy cures this disease. Depending on the severity and chronicity of the disease, the patient may or may not respond to vasodilator therapy. Owing to the complexity of most pulmonary hypertension treatment protocols, preoperative evaluation and optimization by the patient's primary pulmonary physician is desirable whenever possible. The perioperative medical treatment of this disease frequently involves a multidisciplinary (respiratory therapists, pharmacists, nurses, pulmonologist, anesthesiologist, surgeon, etc...) approach and, depending upon the level of specialization of your institution, coordination of these efforts could take considerable 'lead' time. Most patients with PHTN will be categorized as American Society of Anesthesiologists (ASA) Physical Status 4 (Table 2). 


\begin{tabular}{|l|l|}
\hline ASA Physical Status 1 & A patient with mild systemic disease \\
\hline ASA Physical Status 2 & A patient with mild systemic disease \\
\hline ASA Physical Status 3 & A patient with severe systemic disease \\
\hline ASA Physical Status 4 & $\begin{array}{l}\text { A patient with severe systemic disease that } \\
\text { is a constant threat to life }\end{array}$ \\
\hline ASA Physical Status 5 & $\begin{array}{l}\text { A moribund patient who is not expected to } \\
\text { survive without the operation }\end{array}$ \\
\hline ASA Physical Status 6 & $\begin{array}{l}\text { A declared brain-dead patient whose } \\
\text { organs are being removed for donor } \\
\text { purposes }\end{array}$ \\
\hline ASA E & $\begin{array}{l}\text { Emergency operation of any variety (used } \\
\text { to modify one of the above classifications, } \\
\text { i.e., ASA-4E) }\end{array}$ \\
\hline
\end{tabular}

Table 2. ASA Physical Status classifications from the American Society of Anesthesiologists

\section{Perioperative risk}

The patient with pulmonary hypertension (PHTN) is at elevated risk for morbidity and mortality in the perioperative period [Cuenco et al, 1999; Kuralay et al, 2002; Tay et al, 1999; Rodriguez et al 1998]. There is a relative paucity of literature studying outcomes in this population presenting for noncardiac surgery, however, the evidence that does exist points to significantly increased potential for complications in the perioperative period. Ramakrishna et al. presented the results from an overview of 145 patients with PHTN presenting for noncardiac surgery. A $42 \%$ rate of early (<30 days) morbidity and a $9.7 \%$ rate of early mortality in this population have been reported. [Ramakrishna et al, 2005] Clinical characteristics associated with early morbidity and mortality are shown in Table 3.

\begin{tabular}{|c|c|}
\hline $\begin{array}{l}\text { Clinical characteristics of } \\
\text { early mortality }\end{array}$ & $\begin{array}{l}\text { Clinical characteristics } \\
\text { of early morbidity }\end{array}$ \\
\hline 1. Right axis deviation & 1. NYHA class at least 2 \\
\hline 2. Right ventricular hypertrophy & 2. History of pulmonary embolism \\
\hline 3. RVSP/SBP ratio above 0.6 & 3. Obstructive sleep apnea \\
\hline 4. Intraoperative use of & 4. High-risk surgery \\
\hline epinephrine or dopamine & $\begin{array}{l}\text { 5. Anesthesia duration at least } 3 \mathrm{~h} \\
\text { 6. Intraoperative use of epinephrine } \\
\text { or dopamine }\end{array}$ \\
\hline
\end{tabular}

Table 3. Clinical characteristics associtated with increased morbility and mortality in PHTN patients. (Ramakrishna et al, 2005) NYHA = New York Heart Association, RVSP = right ventricular systolic pressure, $\mathrm{SBP}=$ systolic blood pressure.

Lai et al. performed a case-control study examining using 67 cases of patients with pulmonary systolic pressures greater than $70 \mathrm{~mm} \mathrm{Hg}$ compared to controls with normal pulmonary pressures. [Lai et al, 2007] As shown in table 4, the pulmonary hypertension group demonstrated greater postoperative heart failure ( 9.7 vs. $0 \%, \mathrm{p}=.028)$, delayed tracheal extubation ( 21 vs. $0 \%, \mathrm{p}=.004)$ and greater in hospital mortality $(9.7$ vs. $0 \%, \mathrm{p}=.004)$. 
A review of a large U.S. database by Memtsoudis et al. was undertaken to identify mortality in patients undergoing total hip arthroplasty (THA) and total knee arthroplasty (TKA).[Memtsoudis et al., 2010] The authors identified 1359 THA and 2184 TKA patients that also carried the diagnosis of pulmonary hypertension. In comparison to a matched sample without pulmonary hypertension, the THA patients demonstrated a 4-fold increased adjusted risk of in-hospital mortality and the TKA patients demonstrated a 4.5 -fold increase $(\mathrm{p}<.001)$.

\begin{tabular}{llll}
\hline & $\begin{array}{l}\text { Control } \\
(\boldsymbol{n}=\mathbf{6 2})\end{array}$ & $\begin{array}{l}\text { PH } \\
(\boldsymbol{n}=\mathbf{6 2})\end{array}$ & P-value \\
\hline Morbidity (\%) & $2[3.2]$ & $15[24.2]^{*}$ & 0.002 \\
Heart failure (\%) & $0[0]$ & $6[9.7]$ & 0.028 \\
Delayed tracheal extubation $>24$ h (\%) & $2[3.2]$ & $13[21]$ & 0.004 \\
Stroke (\%) & $0[0]$ & $1[1.6]$ & NS \\
Myocardial ischaemia/infarction (\%) & $0[0]$ & $1[1.6]$ & NS \\
Major arrhythmia (\%) & $0[0]$ & $2[3.2]^{* * *}$ & NS \\
Mortality (in-hospital death, \%) & $0[0]$ & $6[9.7]^{* * *}$ & 0.028 \\
\hline
\end{tabular}

Table 4. Postoperative morbidity in patients with Pulmonary Hypertension compared to controls. (Lai et al., 2007) PH= Pulmonary Hypertension (Pulm Syst. BP >70mm Hg)

In summary, patients with PHTN are at considerably increased risk in the perioperative period morbidity and mortality.

\section{Intraoperative considerations}

The right ventricle (RV) is a crescent shaped, thin walled, compliant muscle intended for volume work, not pressure work. Chronic PHTN leads to right ventricular hypertrophy as a compensatory mechanism. However, the ability of the RV to adapt is finite and may eventually lead to RV failure. Unlike the muscular left ventricle, a hypertrophied RV may not tolerate the acute rises in PVR that are associated with pain, surgical stimulation and positive pressure ventilation. RV failure and dilatation can lead to left ventricular compression and diminished cardiac output. This in turn leads to decreased coronary blood flow and perfusion pressure and can become a viscous cycle that can be difficult to overcome. The goals of management are to optimize PAP's, RV preload and to avoid RV ischemia and failure. During anesthesia and surgery, there are significant alterations in all the above parameters and appropriate vigilance and monitoring is essential. Proper operating room monitoring for patients with pulmonary hypertension usually involves placement of arterial and/or pulmonary artery catheters and/or a transesophageal echocardiography probe. Intra-arterial blood pressure monitoring is necessary for beat-tobeat blood pressure monitoring to ensure adequate myocardial perfusion pressures and for frequent blood gas analysis. A pulmonary artery catheter can be used in addition to PCWP to give an indication of left ventricular preload in the patient with PHTN whose cardiac output is limited by right ventricular function. Central venous pressure may be a more accurate guide for volume administration. Additionally, PVR, SVR, and cardiac outputs can be measured and used as guides for volume, vasodilator, or inotropic therapy. Care should be taken in placing these catheters as these patients are reliant on atrial contraction for adequate preload and cardiac output. Arrhythmias associated with catheter insertion may 
not be tolerated well by the patient. Finally, transesophageal echocardiography can be useful to assess the preload and contractility of both right and left ventricles.

\subsection{Echocardiography and pulmonary hypertension}

Echocardiography can be useful for both diagnosis and monitoring of disease progression in pulmonary hypertension $(\mathrm{PH})$. Although transthoracic echocardiography is most widely used for this purpose, transesophageal echocardiography (TEE) can be useful for patients with poor acoustic windows and for intraoperative monitoring. Compared to other monitoring modalities, TEE can be particularly useful in narrowing the differential for intraoperative hemodynamic instability (hypovolemia, hypervolemia, right or left ventricular ischemia/failure) and in formulating a therapeutic plan.

Multiple echocardiographic methods, M-mode, 2D and real-time 3D have been utilized to assess PH. The echocardiographic findings associated with PH include: (i) a diminished or absent atrial wave of the pulmonary valve, (ii) mid-systolic closure or notching of the pulmonary valve, (iii) enlarged right atrial or right ventricular (RV) chambers, (iv) intraventricular septal flattening, (v) paradoxical systolic motion of the intraventricular septum (IVS) toward the left ventricle, (vi) a dilated inferior vena cava with reduced respiratory variability, (vii) increased IVS/posterior left ventricular (LV) wall ratio $(>1)$, (viii) increased RV end-diastolic volume index, (ix) increased RV end-systolic volume index, and (x)decreased RV ejection fraction.[Bossone et al, 2005; Mookadam et al., 2010; Morikawa et al., 2011] Methods to determine pulmonary arterial pressure include: measurement of the tricuspid annular plane systolic excursion (TAPSE), two-dimensional strain, tissue Doppler echocardiography, the speckle tracking method, acceleration time across the pulmonic valve, the pulmonary artery regurgitant jet method and the tricuspid regurgitant jet method. (Janda et al, 2011) The tricuspid regurgitant jet method is the most commonly used for determination of the pulmonary artery systolic pressure (PASP). The simplified Bernoulli equation, $\mathrm{P}_{1}-\mathrm{P}_{2}=4 \mathrm{~V}^{2}$, where $\mathrm{P}_{1}-\mathrm{P}_{2}$ is the pressure gradient and $\mathrm{V}$ is the peak velocity, is used to approximate the PASP by continuous wave Doppler across the tricuspid valve regurgitant jet. In this case, $\mathrm{RVSP} \approx \mathrm{PASP}=4 \mathrm{~V}^{2}+\mathrm{RAP}$, where RVSP is the right ventricular systolic pressure and RAP is the right atrial pressure. The RVSP approximates PASP when no pulmonary valve stenosis or right ventricular outflow obstruction exists. [Janda et al., 2011; Sciomer et al., 2011] Figure 1 demonstrates the enlarged right ventricle, deviated intraventricular septum and compressed left ventricle.

Although right heart catheterization (RHC) remains the gold standard for assessment of hemodynamics in $\mathrm{PH}$, advantages of echocardiography include wide availability, noninvasive modality, and costs. Intraoperatively, TEE allows dynamic interpretation and assessment of the therapeutic management of PH. Disadvantages include the need for specialized training for interpretation, modest diagnostic accuracy and correlation to $\mathrm{PH}$ as compared to RHC.[ Fisher et al., 2009; Janda et al., 2011] Janda et al found the summary correlation coefficient of systolic pulmonary artery pressure (PASP) by echocardiography as compared with PASP by RHC to be 0.70 (95\% CI 0.67 to 0.73 ) as well as a summary sensitivity and specificity of $83 \%$ (95\% CI 73 to 90 ) and $72 \%$ (95\% CI 53 to 85), respectively for diagnostic accuracy of echocardiography for pulmonary hypertension. (Janda et al, 2011) The variability of echocardiography to correlate to RHC is in part due to the underlying disease, lung conditions, time of the examination, and the skills of the echocardiographer. 
[Mookadam et al, 2010; Pedoto \& Amar, 2009; Sciomer et al., 2007] Underestimation of PASP by echocardiography resulting in improper classification of $\mathrm{PH}$ (mild, moderate, severe) is more likely than overestimation, however inaccuracy in both under and overestimation occur with similar frequency. [Fisher et al., 2009] Improvement in obtaining the tricuspid regurgitant jet peak velocity has been found with the use of an intravenous bolus of agitated saline. [Bossone et al., 2005; McLaughlin et al., 2009; Mookadam et al, 2010] Despite the technical challenges and inaccuracies associated with echocardiography, it remains as useful tool for the diagnosis, monitoring, and management of $\mathrm{PH}$.
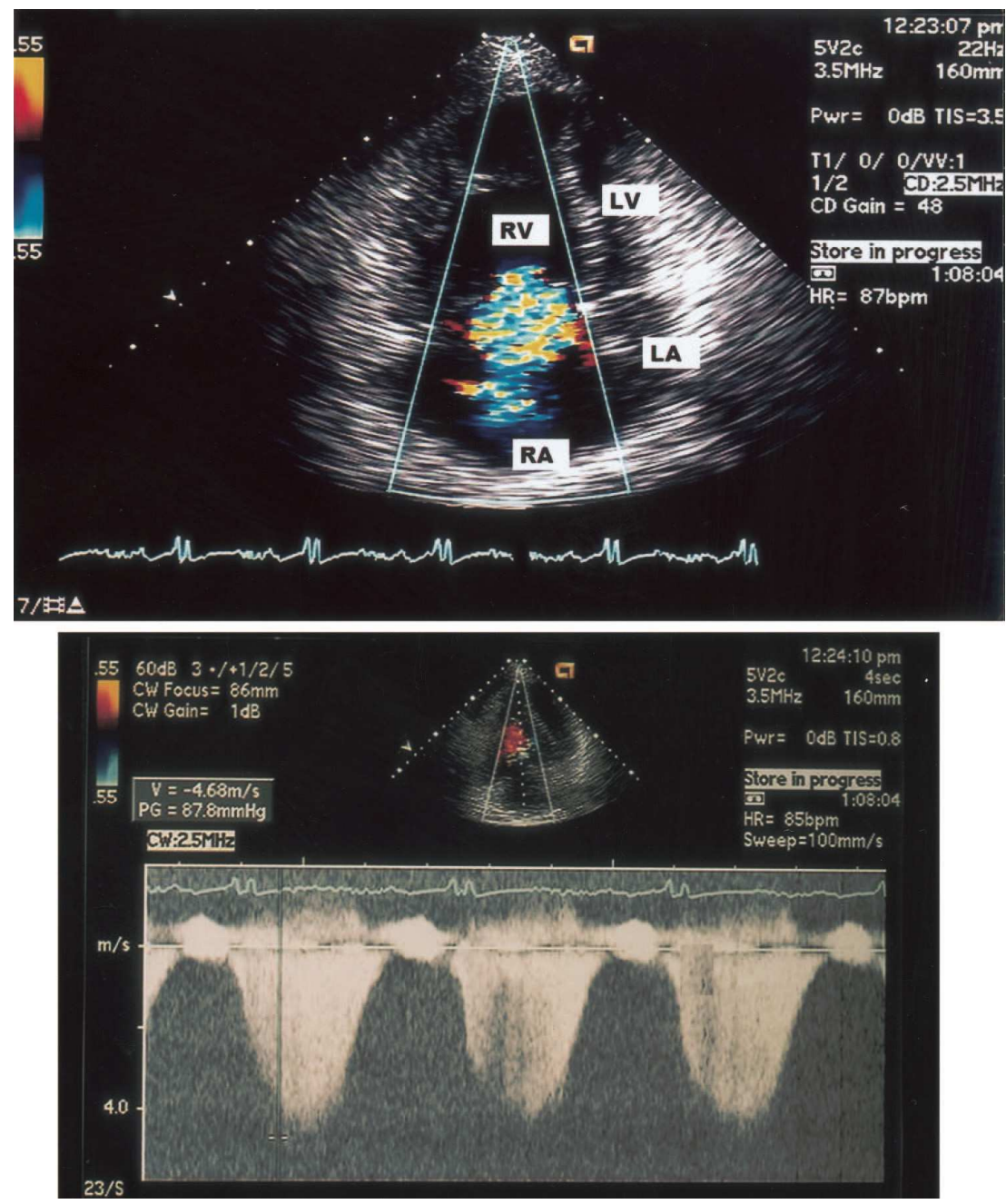

Fig. 1. Top: Apical four-chamber view (systole) showing enlarged right-side chambers with compressed and geometric distortion of an intrinsically normal LV secondary to marked RV pressure overload; severe TR. RA-right atrium; LA- left atrium. Bottom: Peak TR velocity of $4.68 \mathrm{~m} / \mathrm{s}$, with a peak gradient of $87.8 \mathrm{~mm} \mathrm{Hg}$ indicating severe PH. (Bossone et al., 2005) 


\subsection{Anesthetic technique and pharmacological considerations}

Outside of case reports, very little literature exists evaluating management strategies for intraoperative and postoperative management of the patient with pulmonary hypertension. Various management techniques have been described with success including regional, general, and peripheral nerve blockade. [Armstrong, 1992; Martin et al., 2002] The choice of technique is not as important as the ability to adhere to the goals of avoidance of elevations in PVR and right ventricular failure.

\subsubsection{Regional anesthesia}

Regional techniques, including peripheral nerve blockade and neuraxial blockade (epidural, spinal anesthesia) have been successfully utilized in patients with severe pulmonary hypertension. Among the benefits are avoidance of the stimulation of direct laryngoscopy and endotracheal intubation. Even with adequate IV hypnotics, opioids and neuromuscular blockade, it is difficult to avoid increases in sympathetic nervous system activity with direct laryngoscopy. These increases could lead to increases in PVR and potential acute right heart failure. Additionally, during a general anesthetic, with the variable stimulation during the operative procedure, the anesthesiologist is continually managing the balance between excessive sympathetic outflow, increased PVR and potential acute right heart failure on one hand and excessive depth of anesthesia, low cardiac output, low coronary perfusion and cardiovascular collapse on the other hand. (Hohn L et al., 1999) The healthy patient tolerates these variations well, but the patient with severe $\mathrm{PH}$ has limited reserve to tolerate acute increases in PVR or decreased coronary perfusion. A peripheral nerve block technique can limit anesthesia to the specific location of the surgery and avoid the need for the stimulation of intubation and reduced likelihood of sympathectomy and low blood pressure as one would achieve with general anesthesia. An important distinction is that a sympathectomy is still possible when utilizing a regional anesthesia technique such as epidural or spinal anesthesia. This may lead to arterial and venous dilation and reduced preload and cardiac output compromising coronary perfusion.

When utilizing regional or peripheral techniques, it is important to ensure adequate ventilation and oxygenation to prevent increases in PVR. For example, sedation provided to allow the patient to tolerate placement of a peripheral nerve block or to tolerate laying on the narrow, stiff operating table may lead to hypoxemia and hypercarbia secondary to hypoventilation. On the other hand, lack of sedation can promote anxiety, pain and sympathetic stimulation. Finding the appropriate balance can be a challenge for the anesthesiologist.

\subsubsection{General anesthesia}

For major surgery, general anesthesia is still the method of choice and allows for control of ventilation. Commonly used intravenous anesthetics such as propofol and thiopental are associated with hypotension and some myocardial depression. Their use should be judicious. Etomidate has much less an effect on SVR, PVR and myocardial contractility and may be a more useful hypnotic for patient with severe pulmonary hypertension. Use of volatile anesthetics is associated with decreased SVR, myocardial contractility and potential arrhythmias all of which can impair right ventricular myocardial perfusion and also right 
ventricular cardiac output. A balanced technique utilizing high dose narcotics to blunt the cardiovascular response to surgical stimulation and minimal volatile anesthetics can limit these adverse effects. Additionally, the anesthesiologist should strive to use basic physiology to his advantage. These principles include utilization of $100 \%$ oxygen for its pulmonary vasodilator effects, and aggressive treatment of hypercarbia, acidosis, and hypothermia as these all cause pulmonary vasoconstriction. Certain anesthetic agents such as nitrous oxide and ketamine have been associated with increases in PVR and should be used with caution [Rich et al., 1994; Schulte-Sasse et al., 1982].

Intraoperative management of the right ventricle can be made on the presence of RV failure and the presence of systemic hyper- or hypotension. Initially, one should ensure that oxygenation, ventilation, and acid/base status are optimized. Treatment options for PHTN include both intravenous (IV) and inhaled agents. Intravenous vasodilators, such as nitroglycerin, sodium nitroprusside, beta blockers, calcium channel blockers, and certain prostaglandin preparations will cause dilation of both the pulmonary and systemic vascular beds and can be useful in the setting of PHTN with systemic hypertension. The advantages to IV preparations are the relative decreased cost, easier availability of medications, longer duration of action and ease of administration in comparison to inhaled agents.

Milrinone is a phosphodiesterase-3 inhibitor and prevents the breakdown of cyclic adenosine monophosphate (cAMP). It has shown to reduce both PVR and SVR in addition to causing increases in myocardial contractility [Tanake et al, 1991]. If the clinical picture is of pulmonary hypertension with systemic hypotension, IV vasodilators may cause worsening of systemic blood pressure, subsequent RV hypoperfusion, ischemia and failure. In this situation, the patient may benefit from therapy selective for the pulmonary vasculature such as inhaled nitric oxide (INO) or prostacyclin.

INO diffuses from the alveoli to the pulmonary capillaries and acts via stimulation of guanylate cyclase and increasing cyclic guanosine monophosphate (cGMP) leading to vasodilation. INO does not produce systemic vasodilatation because nitric oxide is inactivated when bound to hemoglobin. It also has the benefit of improving ventilationperfusion matching by increasing perfusion to areas of the lung that are well ventilated. INO has been shown to improve PHTN in cardiopulmonary bypass settings [Ichinose et al., 2004; Kavanaugh \& Pearl, 1995]. Prostacyclin, available in inhaled and i.v. forms, stimulates adenylate cyclase and increases cAMP and release of endothelial NO leading to decreases in $\mathrm{PAP}$, right atrial pressures, and increased cardiac output. An example of a prostacyclin nebulized delivery system that can be integrated into the anesthesia circuit is shown in Figure 2. [Jerath, 2010] Combination therapy, with both INO and prostacyclin, has been shown to augment the effects compared to monotherapy [Atz et al., 2002; Petros et al., 1995]. Due to the extremely short half-life of these medications, one should ensure that the medication is delivered continuously without interruption to minimize the risk of rebound pulmonary hypertension. Weaning from these medications should be performed gradually with frequent assessment of pulmonary artery pressures and the right ventricle. A disadvantage of INO compared to inhaled prostacyclin is its cost. A recent analysis revealed that INO is approximately 20 times more expensive than prostacyclin ( $\$ 3000 /$ day vs. $\$ 150 /$ day). [De Wet, 2006]. Table 5 lists the medical management options, including common doses, for intraoperative pulmonary hypertension. Lastly, in patients refractory to the above therapies, right ventricular assist device implantation should be considered. 
1. Ensure good oxygenation, avoid hypercarbia, acidosis and hypothermia

2. Inhaled nitric oxide $20-40 \mathrm{ppm}$.

3. Milrinone (phosphodiesterase III inhibitor) is $50 \mathrm{mcg} / \mathrm{kg}$ bolus, then $0.5-0.75 \mathrm{mcg} \bullet \mathrm{kg}^{-1} \bullet \mathrm{min}^{-1}$

4. Dipiridamole is $0.2-0.6 \mathrm{mg} / \mathrm{kg}$ i.v. over $15 \mathrm{~min}$. Repeat after $12 \mathrm{~h}$.

5. Inhaled prostacyclin: Continuous administration of $50 \mathrm{ng} \bullet \mathrm{kg}^{-1} \bullet \mathrm{min}^{-1}$. Reconstitute prostacyclin in sterile glycine diluent to $30,000 \mathrm{ng} / \mathrm{ml}(1.5 \mathrm{mg}$ of prostacyclin in $50 \mathrm{ml}$ of diluent). For an $80 \mathrm{~kg}$ patient, $50 \mathrm{ng} / \mathrm{kg}$ per min is $8 \mathrm{ml}$ of this solution per hour. It is nebulized into inspiratory limb (see Figure 2).

6. Intravenous prostacyclin (if inhaled is not available) is $4-10 \mathrm{ng}^{\circ} \mathrm{kg}^{-1} \bullet \mathrm{min}^{-1}$.

7. Wean the above medications slowly to prevent rebound pulmonary hypertension.

8. Regional anesthesia can be provided using peripheral nerve blockade, brachial plexus block, and lumbar plexus block.

9. Epidural anesthesia should be induced slowly. Mixtures of local anesthetics and opioids should be given to reduce the dose of local anesthetics and hypotension.

10. Hypotension should be treated according to causes. Phenylephrine and norepinephrine have been used to treat persistent systemic hypotension. Norepinephrine has the advantage of being both a vasoconstrictor and positive inotropic agent. In hypotension, dobutamine and vasopressin have also been advocated for treatment of hypotension [Pearl, 2005; Subramaniam \& Yared 2007].

Table 5. Management options for intraoperative PHTN (modified from Blaise et al., 2003).

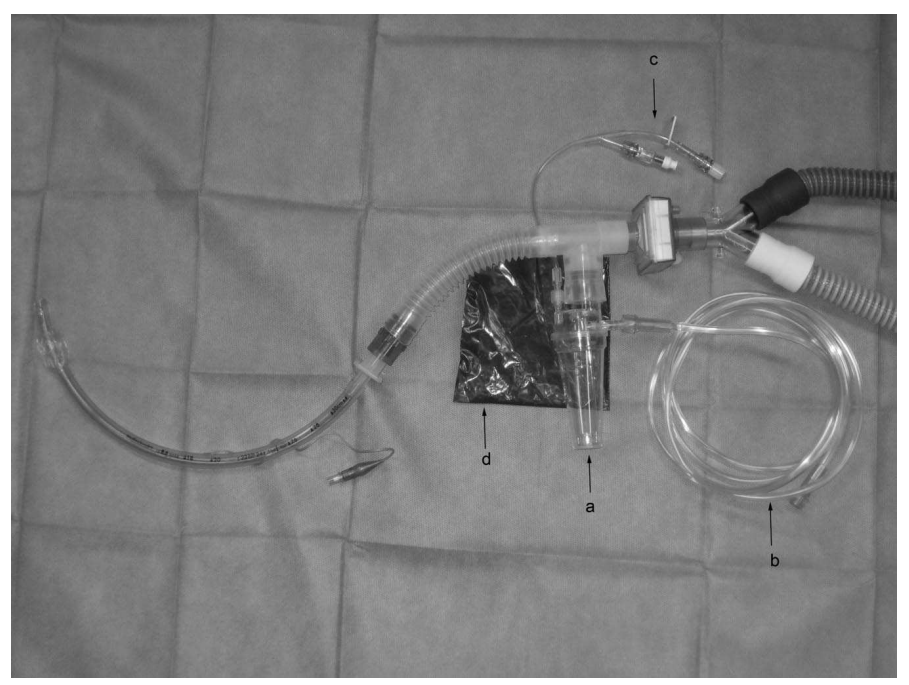

Fig. 2. Inhaled prostacyclin delivery system. Reconstituted prostacyclin is delivered by a Lo-Flo MiniHeart nebulizer (a), which is driven by a separate oxygen source at $2 \mathrm{~L} / \mathrm{min}(\mathrm{b})$. The nebulizer output is $8 \mathrm{~mL} / \mathrm{h}$, which allows for $1-3 \mathrm{~h}$ of continuous nebulization.

The nebulizer should be supported by an IV pole or ventilator side arm to prevent spillage. An IV port (c) allows the chamber to be refilled without disconnecting from the anesthetic circuit. Prostacyclin is photosensitive and requires the nebulizing chamber to be covered from ambient light (d). [Jerath, 2010] 


\section{Postoperative management}

These patients warrant intensive care monitoring in the postoperative period with experienced critical care personnel. As the analgesic and sympathetic nervous system effects of opioids, volatile anesthetics, and regional anesthetics, the patient can develop sudden worsening of PHTN and RV ischemia. Weaning from the ventilator and extubation should be done gradually with close attention to adequate oxygenation, ventilation and analgesia. Even routine events such as bucking on the ventilator due to tracheal stimulation, while tolerated in the average patient, can lead to acute rises in PVR and RV failure in the patient with severe PHTN [Rodriguez \& Pearl, 1998].

\section{Conclusion}

Due to advances in the management of PHTN, it appears likely that these patients will be encountered more frequently in the perioperative period for procedures incidental to their primary disease process. These patients present challenging clinically scenarios secondary to the complexity of their PHTN and are at increased risk for significant perioperative complications. The ideal perioperative care of these patients requires a multidisciplinary approach with appropriate planning for pre-procedure optimization, appropriate resources and monitoring intra-operatively as well as intensive care unit monitoring in the postoperative period. This aggressive approach can test the expertise and resources of medical institutions. Although no curative agent has been identified, the practitioners' knowledge of the existing treatment options, pathophysiology, and the implications of various anesthetic agents and techniques are required to ensure the highest level of patient safety and care.

\section{References}

Ahearn GS, Tapson VF, Rebeiz A, Greenfield JC Jr. Electrocardiography to define clinical status in primary pulmonary hypertension and pulmonary hypertension secondary to collagen vascular disease. (2002). Chest. Vol. 122, No. 2, (August, 2002), pp. 524527, ISSN: 0012-3692

Armstrong P. Thoracic epidural anaesthesia and primary pulmonary hypertension. (1992). Anaesthesia. Vol. 47, No. 6, (June, 1992), pp. 496-499, ISSN: 0003-2409

Atz AM, Lefler AK, Fairbrother DL, et al. Sildenafil augments the effect of inhaled nitric oxide for postoperative pulmonary hypertensive crises. (2002). Journal of Thoracic and Cardiovascular Surgery. Vol. 124, No. 3, (September, 2002), pp. 628-629, ISSN: 0022-5223

Blaise G, Langleben D, Hubert B. Pulmonary arterial hypertension: pathophysiology and anesthetic approach. (2003). Anesthesiology. Vol. 99, No. 6, (December, 2003), pp. 1415-1432, ISSN: 0003-3022

Bossone E, Bodini BD, Mazza A, Allegra L. Pulmonary Arterial Hypertension, The Key Role of Echocardiography. (2005). CHEST. Vol. 127, No. 5, (May, 2005), pp. 1836-1843, ISSN: 0012-3692Bossone E, Paciacco G, Iarussi D, et al. The prognostic role of the ECG in primary pulmonary hypertension. (2002). Chest. Vol. 121, No. 2, (February, 2002), pp. 513-518, ISSN: 0012-3692

Carmosino MJ, Friesen RH, Doran A, Ivy DD. Perioperative complications in children with pulmonary hypertension undergoing noncardiac surgery or cardiac catheterization. 
(2007). Anesthesia and Analgesia. Vol. 104, No. 3, (March, 2007), pp. 521-527, ISSN: 0003-2999

Cuenco J, Tzeng G, Wittels B. Anesthetic management of the parturient with systemic lupus erythematosus, pulmonary hypertension, and pulmonary edema. (1999). Anesthesiology. Vol. 91, No. 1, (August, 1999), pp. 568-570, ISSN: 0003-3022

Davies MJ, Beavis RE. Epidural anaesthesia for vascular surgery in a patient with primary pulmonary hypertension. (1984). Anaesthesia and Intensive Care. Vol. 12, No. 2, (May, 1984), pp. 115-117, ISSN: 0310-057X

De Wet CJ, Affleck DJ, Jacobsohn E, Avidan MS, Tymkew H, Hill 1l, Zanaboni PB, Moazami $\mathrm{N}$, Smith JR. Inhaled prostacyclin is safe, effective, and affordable in patients with pulmonary hypertension, right heart dysfunction, and refractory hypoxemia after cardiothoracic surgery. (2004). The Journal of Thoracic and Cardiovascular Surgery. Vol 127, No. 4, (Aril 2004), pp. 1058-67, ISSN: 0022-5223

Fisher MR, Forfia PR, Chamera E, et al. Accuracy of Doppler Echocardiography in the Hemodynamic Assessment of Pulmonary Hypertension. (2009). American Journal of Respiratory and Critical Care Medicine. Vol. 179, No. 7, (April, 2009), pp. 615-21, ISSN: 1073-449X

Gaine S. Pulmonary hypertension. (2000). JAMA. Vol. 284, No. 24, (December, 2000), pp. 3160-3168, ISSN: 0098-7484

Ichinose F, Roberts JD, Zapol WM. Inhaled nitric oxide: a selective pulmonary vasodilator current uses and therapeutic potential. (2004). Circulation. Vol. 109, No. 25, (June, 2004), pp. 3106-3111, ISSN: 0009-7322

Janda S, Shahidi N, Gin K, Swiston J. Diagnostic accuracy of echocardiography for pulmonary hypertension: a systematic review and meta-analysis. (2011). Heart. Vol. 97, No. 8, (April, 2011), pp. 612-622, ISSN: 1355-6037

Kahn ML. Eisenmenger's syndrome in pregnancy. (1993). New England Journal of Medicine. Vol. 329, No. 12, (September, 1993), p. 887, ISSN: 0028-4793

Kavanaugh BP, Pearl RG. Inhaled nitric oxide in anesthesia and critical care medicine. (1995). International Anesthesiology Clinics. Vol. 33, No.1, (Winter, 1995), pp. 181-210, ISSN: 0020-5907

Krowka MJ, Mandell MS, Ramsay MA, et al. Hepatopulmonary syndrome and portopulmonary hypertension: a report of the multicenter liver transplant database. (2004). Liver Transplantation. Vol. 10, No. 2, (February, 2004), pp. 174-182, ISSN: 1527-6465

Kuralay E, Demirkilic U, Oz BS, et al. Primary pulmonary hypertension and coronary artery bypass surgery. (2002). Journal of Cardiac Surgergy. Vol. 17, No. 1, (January, 2002), pp. 79-80, ISSN: 0886-0440

Lai HC, Lai HC, Wang KY et al. Severe pulmonary hypertension complicates postoperative outcome of non-cardiac surgery. (2007). British Journal of Anesthesia. Vol. 99, No. 2, (August, 2007), pp. 184-90, ISSN: 1471-6771

Loyd JE, Butler MG, Foroud TM, et al. Genetic anticipation and abnormal gender ratio at birth in familial primary pulmonary hypertension. (1995). American Journal of Respiratory and Critical Care Medicine. Vol. 152, No. 1, (July, 1995), pp. 93-97, ISSN: 1073-449X 
MacLean MR. Endothelin-1 and serotonin: mediators of primary and secondary pulmonary hypertension? (1999). Journal of Laboratory and Clinical Medicine. Vol. 134, No. 2. (August 1999), pp. 105-144, ISSN: 0022-2143

Martin JT, Tautz TJ, Antognini JF. Safety of regional anesthesia in Eisenmenger's syndrome. (2002). Regional Anesthesia and Pain Medicine. Vol. 27, No. 5, (September, 2002), pp. 509-513, ISSN: 1098-7339McLaughlin VV, Archer SL, Badesch DB, et al. ACCF/AHA 2009 expert consensus document on pulmonary hypertension: a report of the American College of Cardiology Foundation Task Force on Expert Consensus Documents and the American Heart Association: developed in collaboration with the American College of Chest Physicians, American Thoracic Society, Inc., and the Pulmonary Hypertension Association. Circulation. Vol. 119, No. 16, (April, 2009), pp. 2250-94, ISSN: 0009-7322

Memtsoudis, SG, Ma Y, Chiu, YL et al. Perioperative Mortality in Patients with PulmonaryHypertension Undergoing Major Joint Replacement. (2010). Anesthesia and Analgesia. Vol. 111, No. 5, (November, 2010), pp. 1110-6, ISSN: 0003-2999

Mookadam F, Jiamsripong P, Goel R, Warsame TA, Emani UR, Khandheria BK. Critical Appraisal on the Utility of Echocardiography in the Management of Acute Pulmonary Embolism. (2010). Cardiology in Review. Vol. 18, No. 1, (January 2010), pp. 29-37, ISSN: 1061-5377

Morikawa T, Murata M, Okuda S, et al. Quantitative Analysis of Right Ventricular Function in Patients with Pulmonary Hypertension Using Three-Dimensional Echocardiography and a Two-Dimensional Summation Method Compared to Magnetic Resonance Imaging. (2011). American Journal of Cardiology. Vol. 107, No. 3, (February, 2011), pp. 484-89, ISSN: 0002-9149

Nauser TD, Stites SW. Diagnosis and treatment of pulmonary hypertension. (2001). American Family Physician. Vol. 63, No. 9, (May, 2001), pp. 1789-1798, ISSN: 0002$838 \mathrm{X}$

Pearl RG. Perioperative management of PH: covering all aspects from risk assessment to postoperative considerations. (2005). Advances in Pulmonary Hypertension. Vol. 4, No. 4, (Winter, 2005), pp. 6-15, ISSN: 1933-088X

Pedoto A and Amar D. Right heart function in thoracic surgery: role of echocardiography. (2009). Current Opinion in Anaesthesiology. Vol. 22, No. 1, (Februar,y 2009). pp. 44-49, ISSN: 0952-7907

Petros AJ, Turner SC, Nunn AJ. Cost implications of using inhaled nitric oxide compared with epoprostenol for pulmonary hypertension. (1995). Journal of Pharmacy Technology. Vol. 11, No. 4, (July, 1995), pp. 163-166, ISSN: 8755-1225

Phillips BG, Norkiewk K, Perck CA, et al. Effects of obstructive sleep apnea on endothelin-1 and blood pressure. (1999). Journal of Hypertension.Vol. 17,No. 1, (January, 1999), pp. 61-66. ISSN: 0263-6352

Ramakrishna G, Sprung J, Ravi BS, et al. Impact of pulmonary hypertension on the outcomes of noncardiac surgery: predictors of perioperative morbidity and mortality. (2005). Journal of the American College of Cardiology. Vol. 45, No. 10, (May, 2005), pp. 1691-1699, ISSSN: 0735-1097

Rich GF, Roos CM, Anderson SM, et al. Direct effects of intravenous anesthetics on pulmonary vascular resistance in the isolated rat lung. (1994). Anesthesia and Analgesia. Vol. 78, No. 5, (May ,1994):961-966, ISSN: 0003-2999 
Roberts NV, Keast PJ. Pulmonary hypertension and pregnancy: a lethal combination. (1993). Anaesth Intensive Care.Vol. 18, No. 3, (August, 1993), pp. 366-374, ISSN: 1472-0299

Rodriguez RM, Pearl RG. Pulmonary hypertension and major surgery. (1998). Anesthesia and Analgesia. Vol. 87, No. 4, (October, 1998), pp. 812-815, ISSN: 0003-2999

Ross AF, Ueda K. Pulmonary hypertension in thoracic surgical patients. (2010). Current Opinion in Anaesthesiolology. Vol. 23, No. 1, (February, 2010), pp. 25-33, ISSN: 09527907

Schulte-Sasse U, Hess W, Tarnow J. Pulmonary vascular responses to nitrous oxide in patients with normal and high pulmonary vascular resistance. (1982). Anesthesiology. Vol. 57, No. 1, (July, 1982), pp. 9-13, ISSN: 0003-3022

Sciomer S, Magri D, Badagliacca R. Non-invasive assessment of pulmonary hypertension: Doppler-echocardiography. (2007). Pulmonary Pharmacology and Therapeutics. Vol. 20, No. 2, pp. 135-40, ISSN: 1522-9629.

Subramaniam K, Yared JP. Management of pulmonary hypertension in the operating room. (2007). Seminars in Cardiothoracic and Vascular Anesthesia. Vol. 11, No. 2, (June, 2007), pp. 119-136, ISSN: 1089-2532

Tan HP, Markowitz JS, Montgomery RA, et al. Liver transplantation in patients with severe portopulmonary hypertension treated with preoperative chronic intravenous epoprostenol. (2001). Liver Transplantation. Vol. 7, No. 8, (August, 2001), pp. 745749, ISSN: 1527-6465

Tanake H, Tajimi K, Moritsune O, et al. Effects of milrinone on pulmonary vasculature in normal dogs and dogs with pulmonary hypertension. (1991). Critial Care Medicine. Vol 19, No. 1, (January 1991), pp. 68-74, ISSN: 0090-3493

Tay SM, Ong BC, Tan SA. Cesarean section in a mother with uncorrected congenital coronary to pulmonary artery fistula. (1999). Canandian Journal of Anaesthesia. Vol. 46, No. 4, (April, 1999), pp. 368-371, ISSN: 0832-610X

Tuder RM, Cool CD, Yeager M, et al. The pathobiology of pulmonary hypertension: endothelium.(2001). Clinics in Chest Medicine. Vol. 22, No. 3, (September, 2001), pp. 405-418, ISSN: 0272-5231

Weimann J, Ullrich R, Hromi J, et al. Sildenafil is a pulmonary vasodilator in awake lambs with acute pulmonary hypertension. (2000). Anesthesiology. Vol. 92, No. 6, (June, 2000), pp. 1702-1712, ISSN: 0003-3022

Weiss BM, Atanassoff PG. Cyanotic congenital heart disease and pregnancy: natural selection, pulmonary hypertension, and anesthesia. (1993). Journal of Clinical Anesthesia. Vol. 5, No. 4, (July, 1993), pp. 332-341, ISSN: 0952-8180

Weiss BM, Maggiorini M, Jeni R, et al. Pregnant patient with primary pulmonary hypertension: inhaled pulmonary vasodilators and epidural anesthesia for cesarean delivery. (2000). Anesthesiology. Vol. 92, No. 4, (April, 2000), pp. 1191-1194, ISSN: 0003-3022

Wilkens H, Guth A, Konig J, et al. Effect of inhaled iloprost plus oral sildenafil in patients with primary pulmonary hypertension. (2001). Circulation. Vol. 104, No. 11, (September, 2001), pp. 1218-1222, ISSN: 0009-7322 


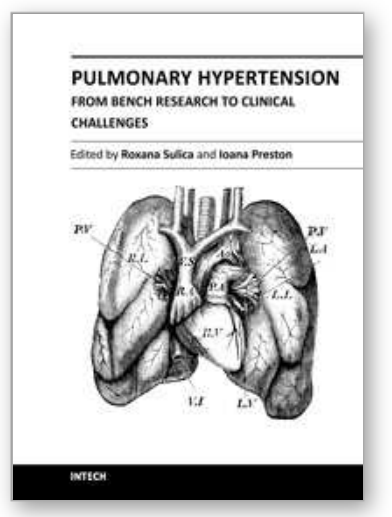

\section{Pulmonary Hypertension - From Bench Research to Clinical Challenges}

Edited by Dr. Roxana Sulica

ISBN 978-953-307-835-9

Hard cover, 326 pages

Publisher InTech

Published online 09, December, 2011

Published in print edition December, 2011

The textbook "Pulmonary Hypertension - From Bench Research to Clinical Challenges" addresses the following topics: structure and function of the normal pulmonary vasculature; disregulated cellular pathways seen in experimental and human pulmonary hypertension; clinical aspects of pulmonary hypertension in general; presentation of several specific forms of pulmonary hypertension, and management of pulmonary hypertension in special circumstances. The textbook is unique in that it combines pulmonary and cardiac physiology and pathophysiology with clinical aspects of the disease. First two sections are reserved for the basic knowledge and the recent discoveries related to structure and cellular function of the pulmonary vasculature. The chapters also describe disregulated pathways known to be affected in pulmonary hypertension. A special section deals with the effects of hypoxia on the pulmonary vasculature and the myocardium. Other three sections introduce the methods of evaluating pulmonary hypertension to the reader. The chapters present several forms of pulmonary hypertension which are particularly challenging in clinical practice (such as pulmonary arterial hypertension associated with systemic sclerosis), and lastly, they address special considerations regarding management of pulmonary hypertension in certain clinical scenarios such as pulmonary hypertension in the critically ill.

\section{How to reference}

In order to correctly reference this scholarly work, feel free to copy and paste the following:

Philip L. Kalarickal, Sabrina T. Bent, Michael J. Yarborough, Kavitha A. Mathew and Charles Fox (2011). Perioperative Management of Pulmonary Hypertension, Pulmonary Hypertension - From Bench Research to Clinical Challenges, Dr. Roxana Sulica (Ed.), ISBN: 978-953-307-835-9, InTech, Available from: http://www.intechopen.com/books/pulmonary-hypertension-from-bench-research-to-clinicalchallenges/perioperative-management-of-pulmonary-hypertension

\section{INTECH}

open science | open minds

\section{InTech Europe}

University Campus STeP Ri

Slavka Krautzeka 83/A

51000 Rijeka, Croatia

Phone: +385 (51) 770447

Fax: +385 (51) 686166

\section{InTech China}

Unit 405, Office Block, Hotel Equatorial Shanghai

No.65, Yan An Road (West), Shanghai, 200040, China 中国上海市延安西路65号上海国际贵都大饭店办公楼 405 单元

Phone: +86-21-62489820

Fax: +86-21-62489821 
www.intechopen.com 
(C) 2011 The Author(s). Licensee IntechOpen. This is an open access article distributed under the terms of the Creative Commons Attribution 3.0 License, which permits unrestricted use, distribution, and reproduction in any medium, provided the original work is properly cited. 